\title{
Electroanalysis with Modified Electrodes: from the Use of Simple Nanomaterials to Engineered Nanohybrids
}

\author{
Luigi Falciola, Valentina Pifferi \\ Gruppo di Chimica ELettroANalitica (ELAN), Dipartimento di Chimica, Università degli Studi di Milano \\ Via Golgi 19, 20133, Milano, Italy \\ Luigi.falciola@unimi.it; Valentina.pifferi@unimi.it
}

In recent years, electroanalysis has witnessed a great growth in the employment of nanomaterials and/or in the use of polymer films to develop smart "modified electrodes", particularly suitable for trace analysis of contaminants of emerging concern [1-2]. High surface to volume ratio, analyte adsorptive preconcentration capability and appropriate nano-dimensions enormously increase the availability of interaction sites for the analyte, enhancing the sensitivity and lowering the detection limits. Moreover, the small dimensions may allow controlling the sensing process locally, in terms of change in the mass transport regime (e.g. from planar to convergent or to thin-layer), improving sensors performances. These effects are particularly maximized in the case of well-ordered structures. Furthermore, the use of appropriately tailored nanohybrids, characterized by synergistic functionalities based on the generation of heterojunctions has paved the way towards promising applications, obtaining "brave new materials", with physico-chemical properties which are not only the sum of the precursors' ones.

In this presentation, experimental results obtained by our group, working with different nanomaterials and nanohybrids for the modification of the electrodes for electroanalytical applications are presented and discussed:

- $\quad$ electrodes modified with appropriately functionalized Carbon NanoTubes (CNT) [3];

- electrodes modified with Sulphonated Poly (Aryl Ether Sulphones), a new class of polymers, ad hoc tailored for electroanalytical applications [4];

- $\quad$ electrodes modified with bimetallic Au/Pd and Au/Pt systems [5];

- photorenewable electrodes based on silver nanoparticles and titania [6];

- (photo)electrochemically active functional hybrids of multilayer CVD graphene decorated with colloidal $\mathrm{TiO}_{2}$ nanocrystals [7];

- (photo)electrochemically active functional hybrids of graphene decorated with colloidal gold nanoparticles.

\section{References}

[1] D.T. Pierce, J.X. Zhao, Trace Analysis with Nanomaterials. Wiley-VCH, 2010.

[2] "Electroanalysis at the Nanoscale", Faraday Discuss., vol. 164, 2013.

[3] V. Pifferi, G. Cappelletti, C. Di Bari, D. Meroni, F. Spadavecchia, L. Falciola, "Multi-Walled Carbon Nanotubes (MWCNTs) modified electrodes: Effect of purification and functionalization on the electroanalytical performances", Electrochimica Acta, vol. 146, pp. 403-410, 2014.

[4] L. Falciola, S. Checchia, V. Pifferi, H. Farina, M. A. Ortenzi, V. Sabatini, "Electrodes modified with sulphonated poly(aryl ether sulphone): effect of casting conditions on their enhanced electroanalytical performance", Electrochimica Acta, vol. 194, pp. 405-412, 2016.

[5] V. Pifferi, C. E. Chan-Thaw, S. Campisi, A. Testolin, A. Villa, L. Falciola, L. Prati, "Au based catalysts: electrochemical characterization for structural insights", Molecules, vol. 21, no. 3, pp. 261, 2016.

[6] G. Soliveri, V. Pifferi, G. Panzarasa, S. Ardizzone, G. Cappelletti, D. Meroni, K. Sparnacci, L. Falciola, "Self-cleaning properties in engineered sensors for dopamine electroanalytical detection,“ Analyst, vol. 140, pp. 1486-1494, 2015. 
[7] C. Ingrosso, G. V. Bianco, V. Pifferi, P. Guffanti et al., "Enhanced Photoactivity and Conductivity in Transparent $\mathrm{TiO}_{2}$ Nanocrystals/Graphene Hybrid Anode", J. Mat. Chem. A, in press, 2017. 